\title{
Regional Disparities in Sedentary Behaviors and Meal Frequency in Iranian Adolescents: The CASPIAN-III Study
}

\author{
Fereshteh Baygi ${ }^{1}$; Ramin Heshmat ${ }^{2}$; Roya Kelishadi ${ }^{3}$; Fatemeh Mohammadi ${ }^{4}$; Mohammad \\ Esmail Motlagh ${ }^{5}$; Gelayol Ardalan ${ }^{6}$; Hamid Asayesh ${ }^{7}$; Bagher Larijani ${ }^{1}$; Mostafa Qorbani ${ }^{8,2,}$ \\ ${ }_{1}^{1}$ Endocrinology and Metabolism Research Center, Endocrinology and Metabolism Clinical Sciences Institute, Tehran University of Medical Sciences, Tehran, IR Iran \\ ${ }_{3}^{2}$ Chronic Diseases Research Center, Endocrinology and Metabolism Population Sciences Institute, Tehran University of Medical Sciences, Tehran, IR Iran \\ ${ }^{3}$ Department of Pediatrics, Child Growth and Development Research Center, Research Institute for Primordial Prevention of Non-Communicable Disease, Isfahan University of \\ Medical Sciences, Isfahan, IR Iran \\ 4 Department of Food and Nutrition Policy and Planning Research, National Nutrition and Food Technology Research Institute, Faculty of Nutrition Sciences and Food Technology, \\ Shahid Beheshti University of Medical Sciences, Tehran, IR Iran \\ 5 Department of Pediatrics, Ahvaz Jundishapur University of Medical Sciences, Ahvaz, IR Iran \\ 6 Department of School Health, Bureau of Population, Family and School Health, Ministry of Health and Medical Education, Tehran, IR Iran \\ 7 Department of School Heal th, Bureau of Population, Family and School Health, Ministry \\ 8 Department of Medical Emergencies, Qom University of Medical Sciences, Qom, IR Iran
Department of Community Medicine, Alborz University of Medical Sciences, Karaj, IR Iran \\ *Corresponding author: Mostafa Qorbani, Department of Community Medicine, Alborz University of Medical Sciences, P. O. Box: 1599666615, Karaj, IR Iran. Tel: +98-2188913543, \\ E-mail: mqorbani1379@yahoo.com
}

Received: January 1, 2014; Accepted: September 28, 2014

Background:The prevalence of obesity is increasing among Iranian youngsters like other developing countries.

Objectives: This study was conducted to assess regional disparities in sedentary behaviors and meal frequency in Iranian adolescents.

Patients and Methods: In this national survey, 5682 students aged 10 - 18 years from urban and rural districts of 27 provinces of Iran were selected via stratified multi-stage sampling method. The country was classified into four sub-national regions, based on criteria of the combination of geography and socioeconomic status (SES). Mean of meal frequency and physical activity levels as well as prevalence of omitting meals and sedentary behavior were compared across regions with different SES after stratifying with sex and age group.

Results: Meal frequency in lower socio-economic regions was significantly higher than two other regions in 10 - 13 and 10 - 18 years old groups ( $\mathrm{P}$ trend $<0.001)$. However, the mean of working hours with computer was linearly increased with increasing the SES in studied regions ( $\mathrm{P}$ trend $<0.001$ ), whereas the corresponding figure was not significant for the mean of watching TV (Ptrend $>0.05$ ). Frequency of adolescents omitting their meals was higher in higher SES regions especially in West Iran $(\mathrm{P}<0.001)$ in 10 - 13 years old age group. Having personal computer and working with it more than two hours per day mainly was observed in central Iran which ranked as the highest SES group.

Conclusions: Efforts to ensure Iranian youth meet healthy food habits and screen time guidelines include limiting access to screen technologies and encouraging parents to monitor their own screen time is required.

Keywords: Adolescent; Obesity; Behavior

\section{Background}

The prevalence of obesity is increasing among Iranian youngsters like other developing countries $(1,2)$. A complex interaction between environmental and behavioral factors is known to be underlying cause of childhood obesity (3). Sedentary behaviors (television, video and computer) are related to health outcomes independent of physical activity, because sedentary behaviors may displace the available time for participation in physical activity, resulting in overall lower energy expenditure (4). Some of the studies revealed that the obesogenic effect of television (TV) viewing in youngsters may be due to increasing food intake than to decreased physical activity levels $(5,6)$. Also, snacking play an important role in emerging of overweight and obesity (7). Some of the dietary behaviors linked with obesity are as follows: increased number of meals eaten outside home (8), larger portion sizes of meals at restaurants and fast-food takeaways (9), and increased consumption of soft drinks (10, 11). Sociodemographic factors may be explaining the association between sedentary behaviors and food intake. Families with lower economic status buy less-nutritious, energy-dense foods owing to their reduced cost. These families may prefer watching TV during their leisure time (12). Information about the contexts of snacking in adolescents or how snacking may influence other dietary habits, like meal skipping is lacking. Also few studies have examined trends of sedentary behaviors among youth in developing nations.

Copyright (C) 2015, Growth \& Development Research Center. This is an open-access article distributed under the terms of the Creative Commons Attribution-NonCommercial 4.0 International License (http://creativecommons.org/licenses/by-nc/4.0/) which permits copy and redistribute the material just in noncommercial usages, provided the original work is properly cited. 


\section{Objectives}

This study is conducted to compare the mean of meal frequency and physical activity level in a nationally representative sample of Iranian adolescents living in different regions with diverse socio-demographic patterns and to determine whether meal and snacking patterns are associated with gender, age level, or region of residence.

\section{Patients and Methods}

This national level cross-sectional study was performed in 2009 - 2010 as the third survey of the school-based surveillance system entitled Childhood and Adolescence Surveillance and PreventIon of Adult Non-communicable Disease (CASPIAN-III) Study in Iran. It was a multicentre study performed among 5682 school students (96\% participation rate), aged 10 - 18 years, living in urban and rural areas of 27 provinces in Iran. Details on the study protocol have been described before $(13,14)$ and here we report it in brief. Approval for the study was granted by ethics committees and other relevant national regulatory organizations. The Data and Safety Monitoring Board of the project closely supervised the quality control and quality assurance of the survey at the national level. The project team obtained written informed consent from parents and oral assent from students. They selected school students by multistage random cluster sampling. Schools were stratified according to location (urban or rural), and the socioeconomic characteristics of their catchment area, taking into consideration the proportion of the different types of schools (public or private) to avoid socioeconomic bias. Questionnaires in the Farsi language were prepared based on the questionnaires used in the WHO STEP-wise approach to non-communicable diseases (Tools version 9.5) and the WHO Global School-based Student Health Survey (GSHS). Students filled in a validated food frequency questionnaire. The validity of our questionnaire's content was affirmed by a panel of experts; item analysis and reliability measures were assessed in a pilot study. Data on physical activity level and time screen of students was gathered through a questionnaire. The students' PA pattern was assessed by the questionnaire in which nine different metabolic equivalent (MET) levels were ranged on a scale from sleep/rest (0.9 METs) to high-intensity physical activities (>6 METs); this instrument was assessed by comparison with measurement of physical activity by accelerometry and keeping a PA diary (15). The questionnaire had previously been modified and validated among Iranian young people (16), and was found to be significantly associated with the results obtained using the International Physical Activity Questionnaire (IPAQ) (17). For each activity level, the MET-value was multiplied by the time spent at that particular level. The MET-time at each level was added to obtain a total over 24 hours MET-time, representing the PA level on an average weekday. Energy expenditure was estimated by multiplying the total 24-hour MET-time by the body weight. In the current study, we categorized the PA level according to the tertiles computed in the population studied, and scored it from one to three corresponding to the first to the third tertile. The data entry staff entered data for all forms. And questionnaires twice and checked for completeness and inconsistencies. The data checking process was conducted first at the district and then at the national level (13). Classification of Iran into four sub-national regions was based on previously published paper by Farzadfar et al. (18). The sub-national regions were defined based on criteria of the combination of geography and SES using principal component analysis. According to this classification, the Southeast and the Central region have the lowest and highest SES, respectively. SES was an index consisted of variables from the 2006 census, including literacy, family permanent income (family assets) and employment rate.

\subsection{Statistical Analyses}

Continuous and categorical variables are expressed as mean (standard deviation) and number (percentage), respectively. The differences in prevalence of meal frequencies, time spent watching television and/or at a computer across regions were tested by using the Pearson Chi-square test. Comparison of means of these variables across regions was investigated by ANOVA; significant findings were further analyzed using post hoc tests (Tukey). A P value of $<0.05$ was considered as statistically significant. All statistical analyses were performed using programs available in the STATA package.

\section{Results}

The participants of this study included 5682 students aged 10 - 18 years old. The number of subjects in Southeast (lowest SES), North-Northeast (second low SES rank), West (second high SES rank) and Central (highest SES) regions were 567 (10.0\%), 1075 (18.9\%), 2372 (41.7\%) and 16618 (29.4\%), respectively. No significant difference was found in age and sex ratio across the regions $(P>0.05)$. Table 1 shows the mean daily meal frequency, hours of watching TV, working with computer, and screen time activity of adolescent participants of the study based on their sex and age group. Meal frequency in lower socio-economic regions (Southeast and North-Northeast) was significantly higher than in two other regions (West and Central) in $10-13$ and 10 - 18 years old groups (P trend $<0.001$ ). However, the mean of working hours with computer was linearly increased as the SES of regions increased ( $P$ trend $<0.001$ ), whereas the corresponding figure was not significant for the mean of watching TV (P trend > 0.05). Nearly mean of all three variables shown in Table 1 was significantly higher in girls compared to boys in different age groups and regions except for the lowest SES region. Frequency of adolescents omitting meals was higher in higher SES regions especially in West Iran $(\mathrm{P}<0.001)$ in 10 - 13 years old age group and as SES increased between 
regions, male adolescents omitted their meals more than did girls (Table 2). Having personal computer and working with it more than two hours per day mainly was observed in central Iran which ranked as the highest SES group. North-Northeast and West were similar regarding these variables and adolescents residing in Southeast region had the lowest working with computer (Table 3), as well as physical activity between regions. Both physical activity hours per day and participation in a sport class at school were higher in male than in female subjects and in central region-which was the highest SES-compared to other regions (Table 4 ).

\section{Discussion}

To our best knowledge, this is the first study in developing countries to address identifying the meal frequency pattern and sedentary behavior in adolescent of subnational regions of Iran and one of the few in the international literature. Regarding physical activity level, our study focused on some key behaviors such as watching TV, using computer, and playing video games. Based on our findings, having personal computer and working with it mainly was observed in central Iran which ranked as the highest SES group. North-Northeast and West were similar regarding these variables and adolescents residing in Southeast region had the lowest working with computer among regions. The opposite association observed between SES group and computer use may be related to economical access. That is, families residing in lower SES regions may not be able to afford a home computer. A study conducted by Carson et al. revealed that girls living in low SES neighborhoods engaged in significantly more weekly screen time and TV/movie minutes compared to girls living in high SES neighborhoods. Consistent with our study, children living in low SES neighborhoods were more likely to use video games and less likely to use computers compared to children living in high SES neighborhoods. Also, children living in medium SES neighborhoods were less likely to use computers compared to children living in high SES neighborhoods (19). A few studies that have assessed temporal trends in screen time among children in developed nations, revealed that a significant increase in both screen time and the proportion of youngsters spending two or more hours per day on screen time over the last decade (20-22). These trends are consistent with previous studies from developed countries $(20,21)$, but reveal more rapid increases than previously reported because of economic transitioning which is occurring in these countries. Rapid increase in the family income has caused ownership of televisions, video players and computers, and prevalence of child obesity (23). There are not data on trends of sedentary behaviors among Iranian children or adolescents and only small cross-sectional assessments were conducted on this regard. Future studies should examine the physical activity level changes of these age groups after efforts for design- ing screen time guidelines. Studies among Western youth in the developed countries such as USA (24), UK (25), France (21), Canada (26) and Australia $(27,28)$ conducted between 1999 and 2006, have reported that the average screen time among Western youth was approximately 2.5 hours per day. In Mexico City, youth watched TV for 2.4 hours per day and videos for 0.9 hours per day in 1997, with a $40 \%$ of youth exceeding the screen time guidelines (29). Daily mean of national screen time in our study was about 2.8 hours and was similar to other studies in developing countries reported 2.7 hours per day of screen time among their youth in 2005 - 2006 (30). These findings are in contrast to other findings from Asian based studies that indicate screen time is lower among youth in a range of Asian countries compared with Western and South American youth. However, screen use in Asia was related to the economic prosperity of the country $(4,31)$ and in the present study it was different in the four SES based regions in the country. One of the first studies in Latin America showed an increase of 60 minutes in the overall screen time from age 11 to 15 years. Also, using computer increased, TV viewing declined, and no changing was observed in time spent playing video games. Boys reported more hours of screen time than girls (32). Our study revealed that screen time increased in early adolescents, consistent with above study. Greater screen time among boys in comparison with girls was observed. A study conducted in Australia revealed that watching TV/videos/DVDs and using computer for fun were the most popular sedentary behavior among students, corresponding with more than one-half of all sedentary time spent by Australian adolescents (28). In a study of American adolescents, no difference in mean time of watching TV/video between sexes was observed. However, boys spent more time playing computer games than girls, whereas girls spent more time sitting and listening to music and talking on the telephone than boys (33). In Spanish children, males also spent more time for playing computer games and engaged in more time spent in all screen-viewing behaviors than females (34). A systematic review involving only prospective studies revealed that there is insufficient evidence for the socioeconomic determinants of sedentary behavior (35). Consistent with other studies we found sedentary activities differed between boys and girls $(36,37)$. Therefore future screen time and sedentary behavior research among children and adolescents should be consider the moderating effects of gender as well as assessing explanations for these effects. Our study explored meal frequency of adolescents and the association of region with skipping meals. Frequency of adolescents omitting their meals was higher in higher SES regions especially in West Iran in 10 - 13 years old age group and as SES increased between regions; male adolescents more omitted their meals than girls. The increasing prevalence of snacking has been considered as a potentially important influence on energy regulation and rapid increasing of obesity in adolescents (38). 


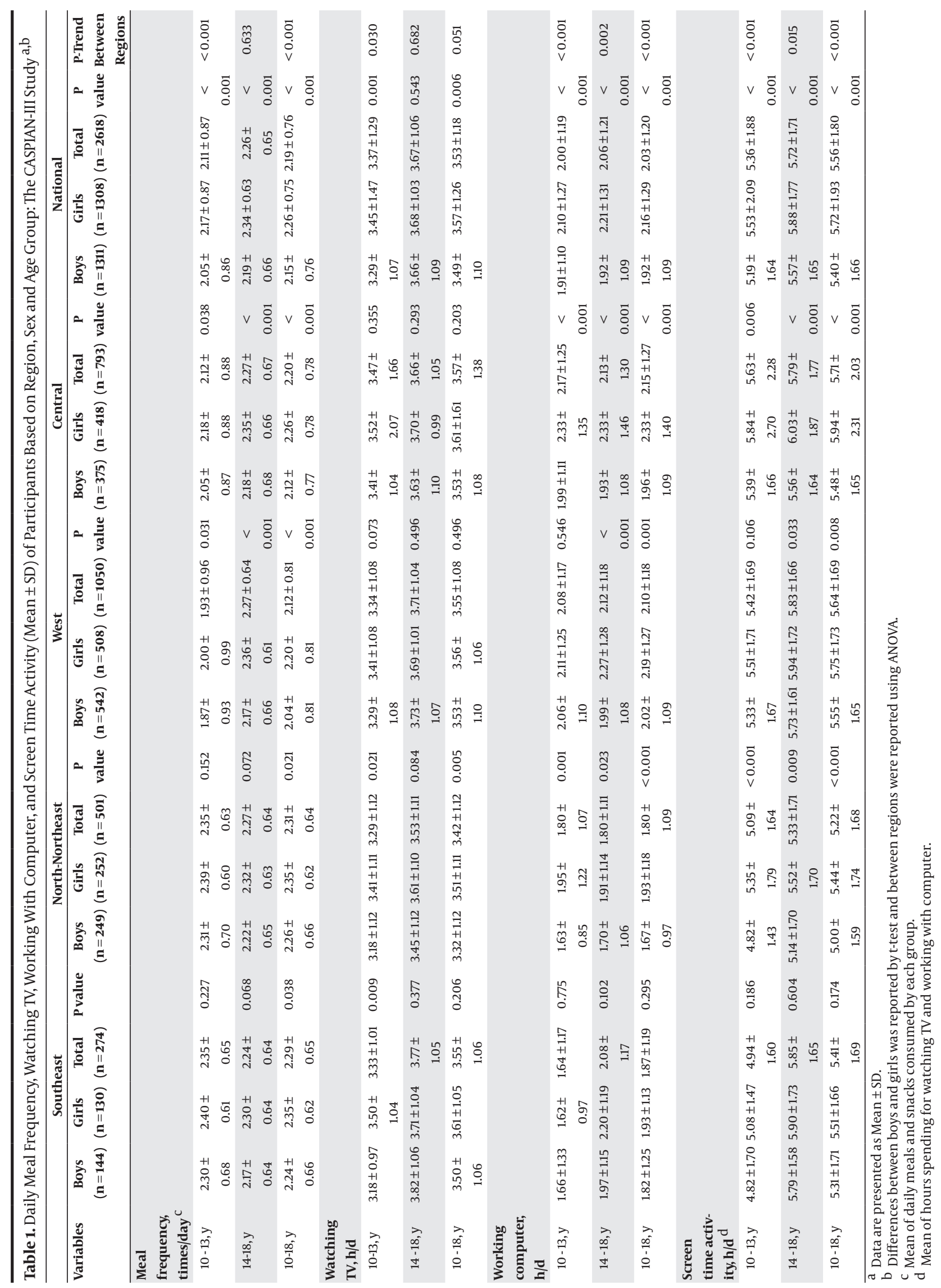




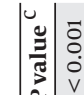

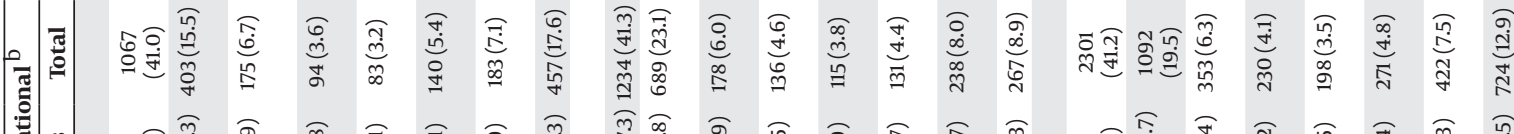

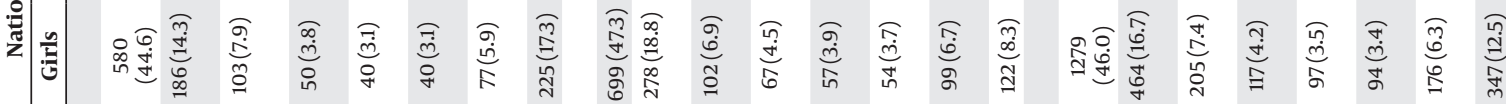

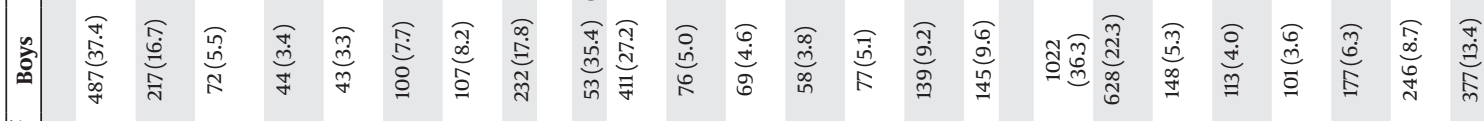

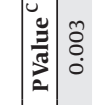

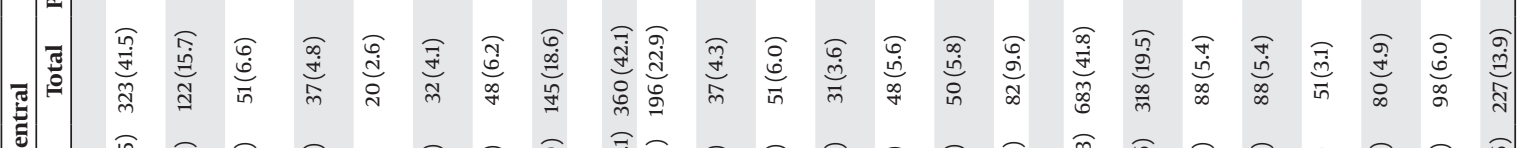

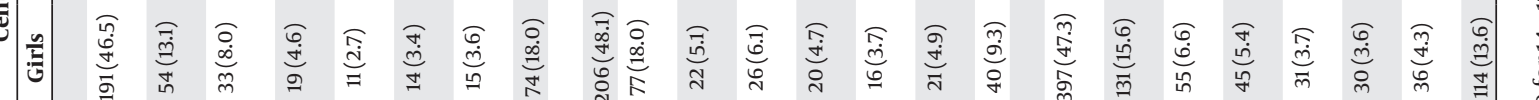

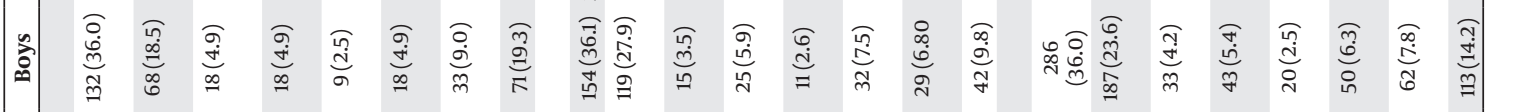

辛

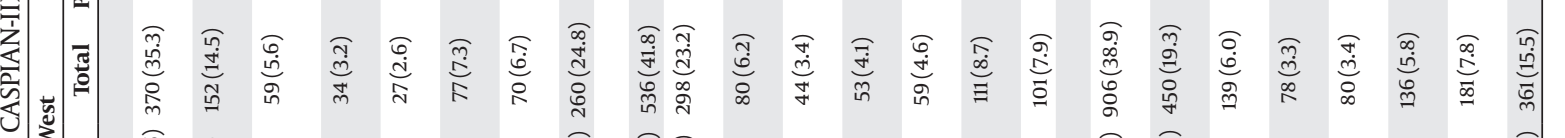

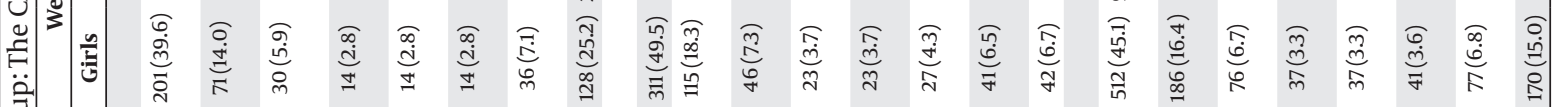

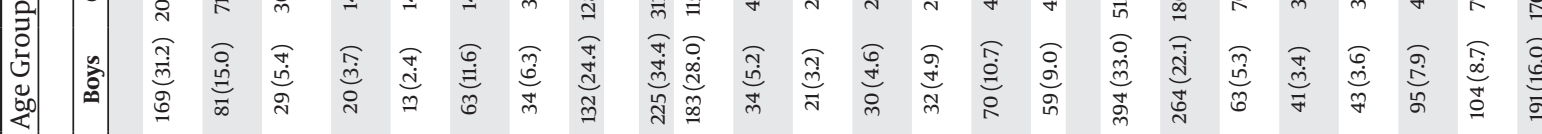

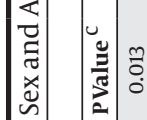

\section{苍}

⿳亠丷厂犬

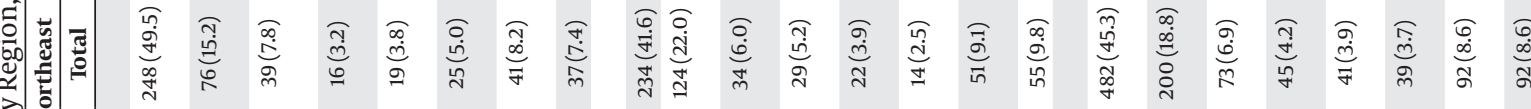

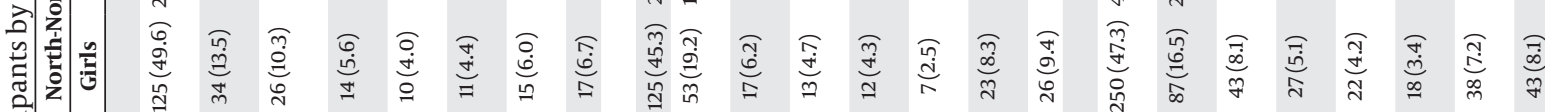

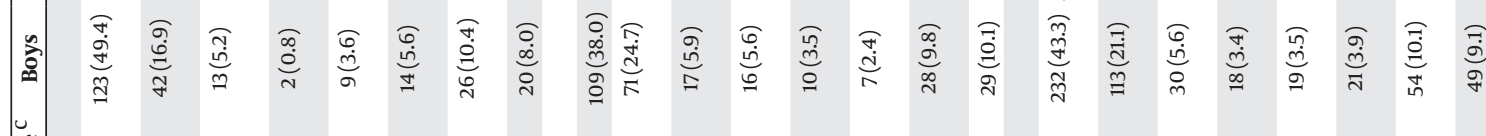

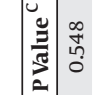

疍

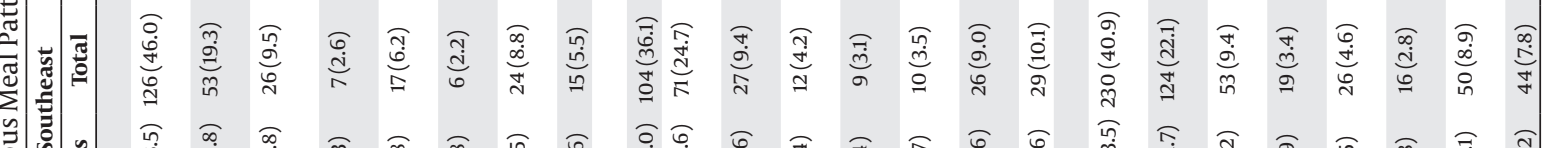

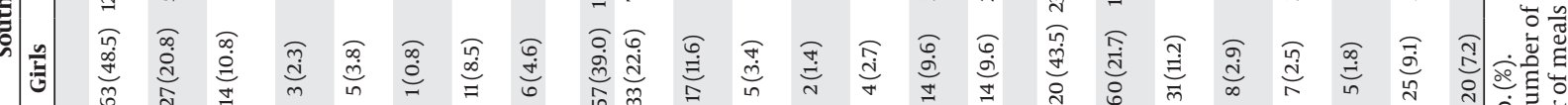

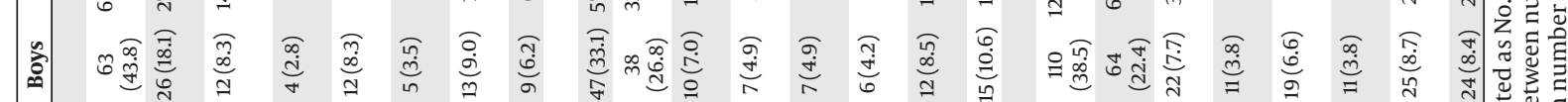

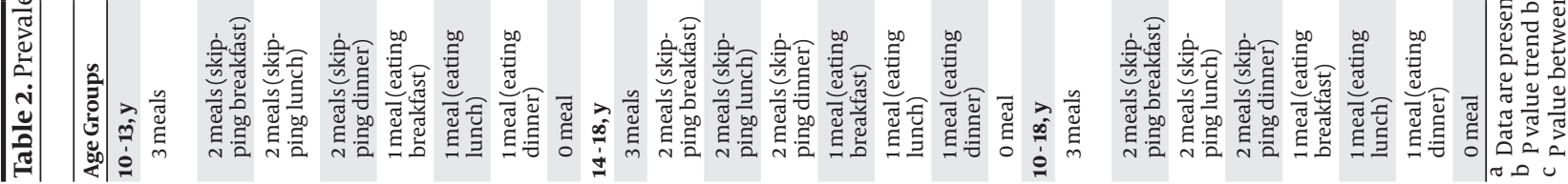




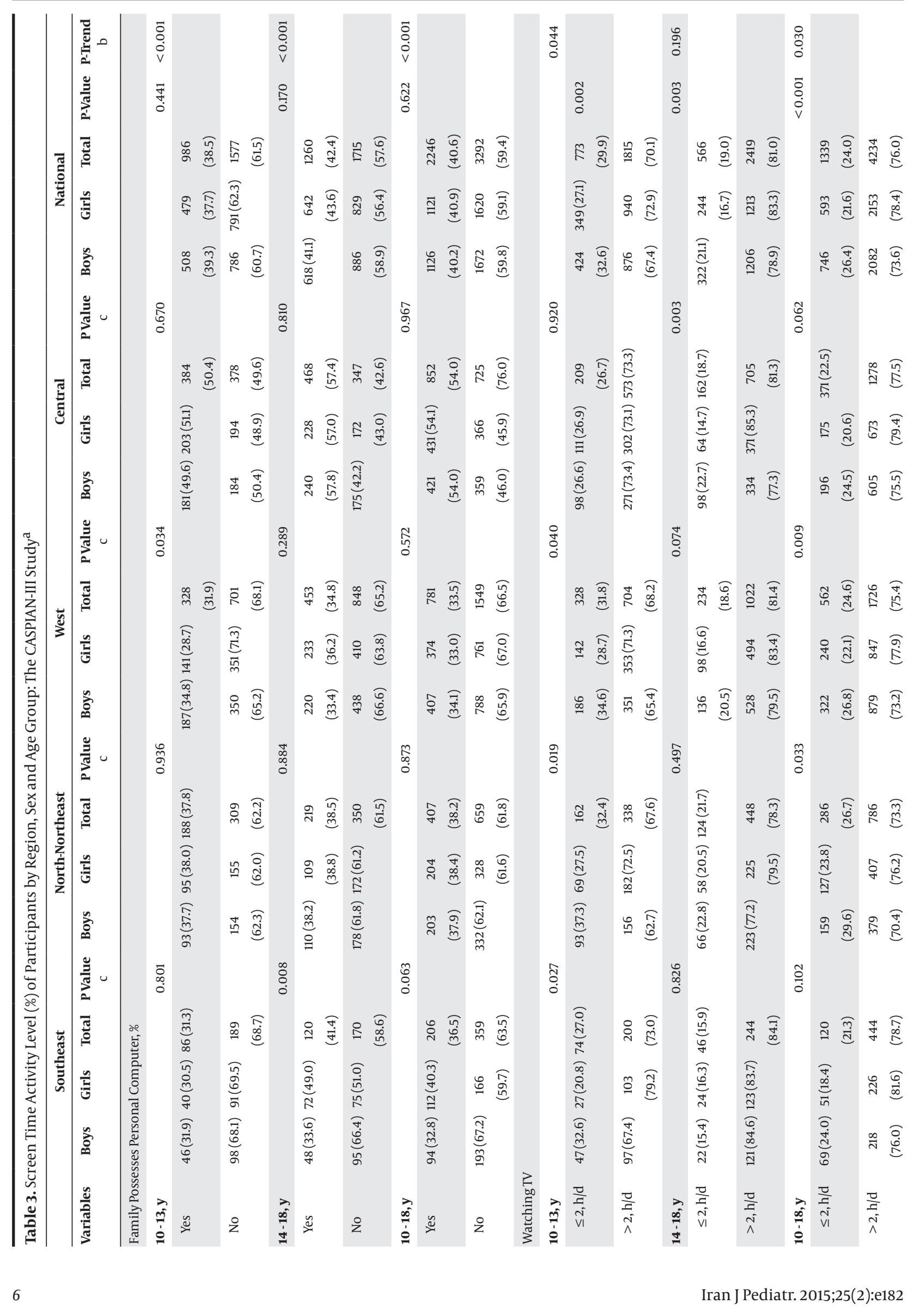



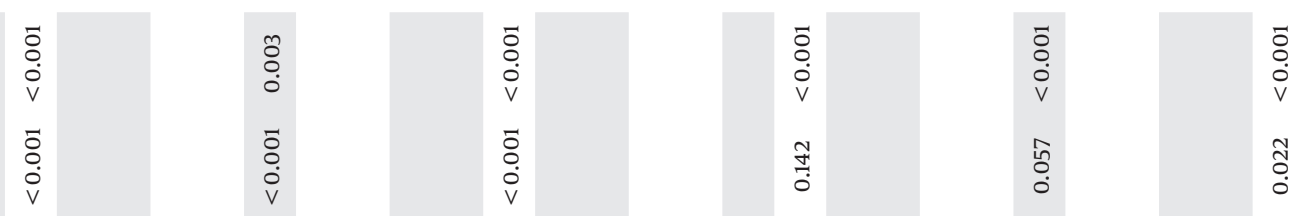

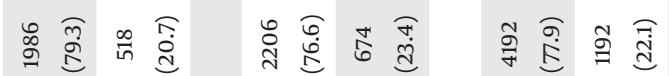

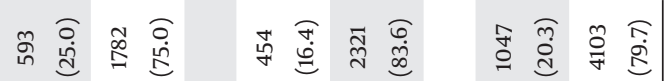

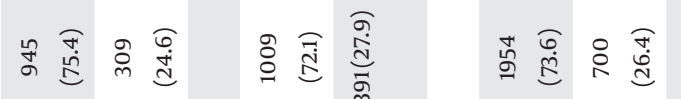

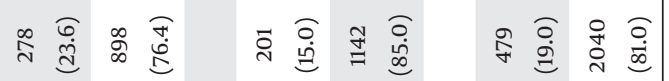

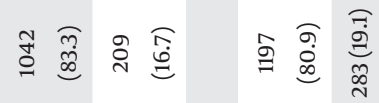

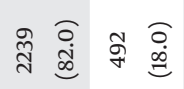
宫

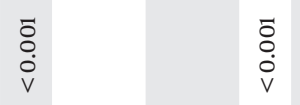

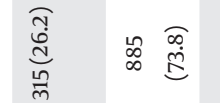

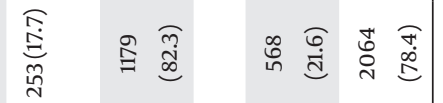
ஓ

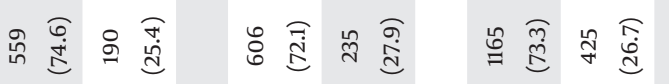

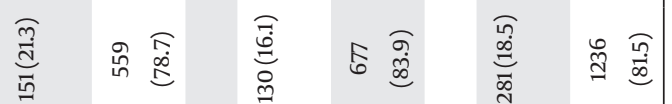

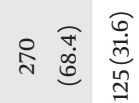

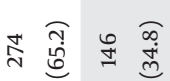

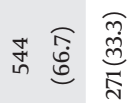

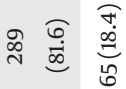

议

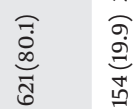

$\stackrel{\dddot{m}}{0}$

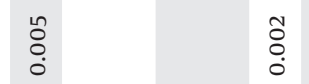

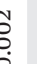

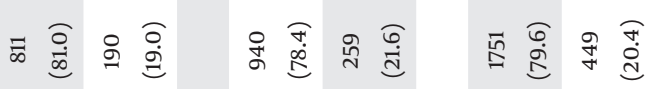
व

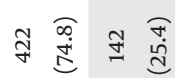

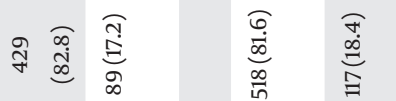

○ें :

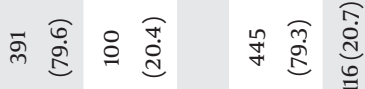

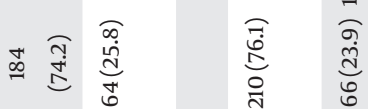

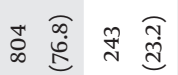

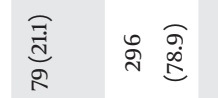

宮

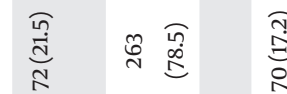

商

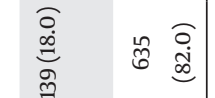

号

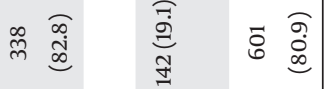

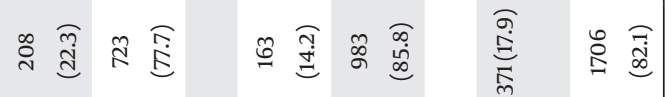

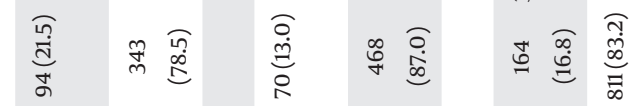

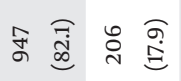

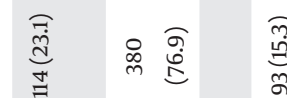

্ֻ]

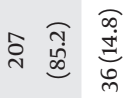

讪拿高

宫

œ

䔍

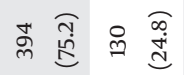

只蛋

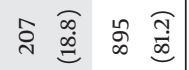
旁

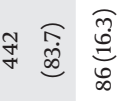

总

苟

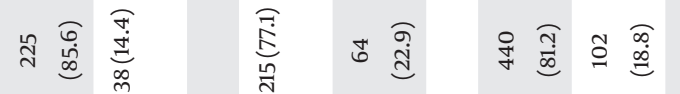

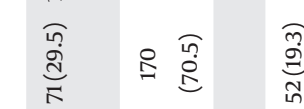

$\stackrel{\substack{0 \\:}}{\circ}$

\section{.}

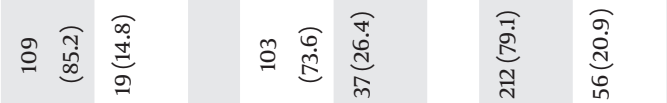

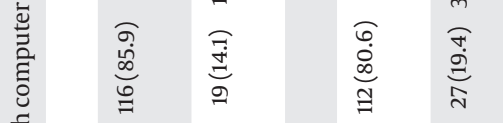

สำ 总

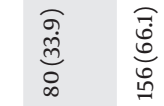

年

:ัّ

哭

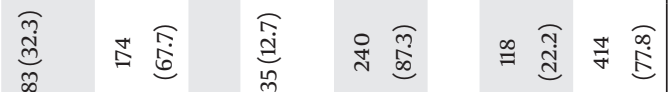

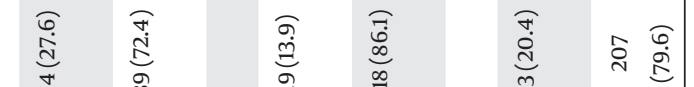

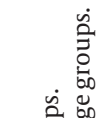

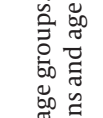

焉 


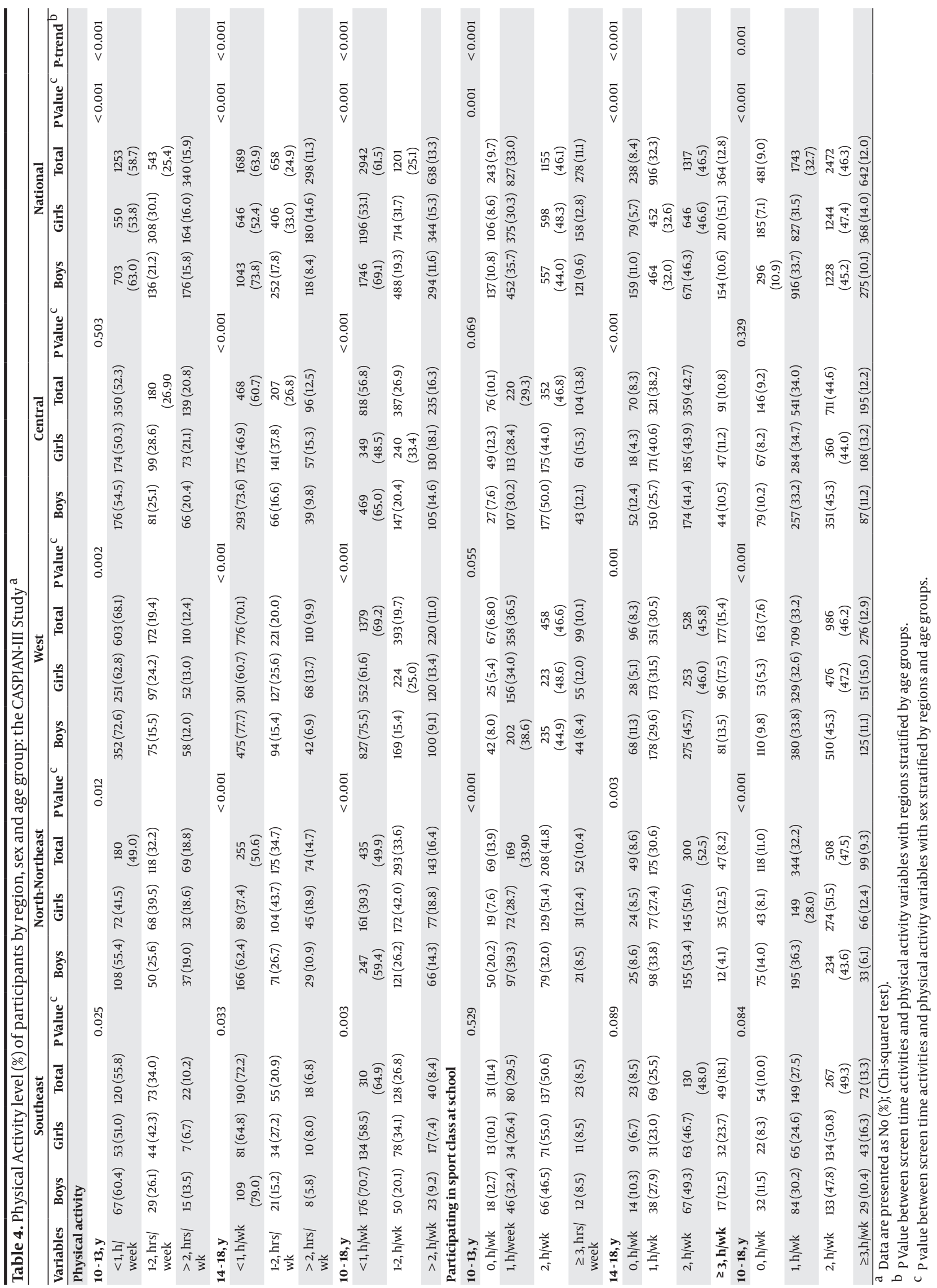


Many studies revealed a positive association between lower SES and incorrect dietary behaviors like meal skippin (39-41). Other recent studies revealed that eating regularly and not skipping meals have a positive effect on overall quality of life such as academic performance, energy, and emotional functioning $(42,43)$. In one Australian study, the most commonly reported reasons for skipping breakfast in adolescents included: a lack of time in the morning (52\%) and not being hungry (22\%). Researchers think snacking on the run and on the way to or from school could be associated with a lack of time and support their finding that snacking in these contexts increased the likelihood of skipping breakfast in adolescents, compared with adolescents who did not snack in these contexts (44). Some Korean studies assessed the various factors that may be associated with adolescents' meal skipping, such as accurate knowledge of nutrition, residential district, parents' job and cigarette smoking, along with the variables like SES (45, 46). These mentioned factors turned out to be important variables in above research as well. An Australian survey demonstrated that more adolescents skipped breakfast (20\%) than skipped lunch $(12 \%)$ or dinner $(2 \%)$. Meal skipping was associated with gender and region of residence which is similar to our findings. Females were more likely than males to report skipping breakfast and lunch on most days. Also, adolescents from metropolitan regions compared with non-metropolitan adolescents were more likely to report skipping breakfast on most days. Meal skipping was associated with gender and region of residence. Skipping breakfast and lunch in females were more than in males. Similarly, adolescents in metropolitan areas were more likely than their peers from nonmetropolitan areas to skip breakfast (5). Some more studies have also reported a higher frequency of breakfast skipping among female adolescents (44, 47). Recently in a study of meal skipping patterns among fourth grade children from distinct geographical locations in Maryland, USA, researchers found that urban students were more likely to skip breakfast compared with suburban and rural students (48). Based on our findings, Iranian adolescents especially in lower SES regions, did not have proper meal frequency, screen time and physical activity level which can led to health problems including non- communicable disease in later life. Therefore, efforts to ensure Iranian youth meet healthy food habits and screen time guidelines-include limiting access to screen technologies-and encouraging parents to monitor their own screen time is required.

\subsection{Study Limitations and Strengths}

Major strength of this study was large-scale sample size which was studied to represent Iranian adolescents in nationwide survey. The sampling and data collection methods were identical in sub-national regions, too. In addition, this study provides a valuable body of informa- tion about screen time, physical activity levels and meal frequency of adolescents living in different regions of Iran. However, we cannot assume the certain contexts of snacking in subjects (e.g. in the middle of the night, on the way to or from school). Also, since we did not ask students to indicate what kind of foods or drinks they consumed as snacks, we are unable to determine if the nutritional quality of the snacks varied according to the context of snack. So, future research should be assessing whether adolescents consume different types of snacks in different snacking contexts. For example, are adolescents more likely to snack on energy dense foods (chips, chocolate) while watching TV, fruit while doing homework, and milk in the middle of the night?

In conclusion, from a public health perspective, our findings have potential implications for interventions designed to reduce screen time among adolescents. Further studies are needed to expand the body of evidence on predictors and health consequences of screen-time change among adolescents. Future interventions may need to consider environmental factors and be gender specific. In addition, programs to reduce screen time must address the roles of parents and socioeconomic characteristics of families in different regions of Iran.

\section{Acknowledgements}

The authors are thankful to the large team working with this study, as well as the participants and their families.

\section{Authors' Contributions}

Concept/design: Roya Kelishadi, Ramin Heshmat, Mostafa Qorbani; Acquisition of data: Fereshteh Baygi, Gelayol Ardalan; Data analysis/interpretation: Mostafa Qorbani, Roya Kelishadi, Fereshteh Baygi, Fatemeh Mohammadi, Mohammad Esmail Motlagh; Manuscript preparation: Fereshteh Baygi, Fatemeh Mohammadi, Mostafa Qorbani; Critical revision of the manuscript: Roya Kelishadi, Ramin Heshmat; Funds collection: Mohammad Esmail Motlagh, Roya Kelishadi, Ramin Heshmat; Approval of the Article: All of the authors.

\section{Funding/support}

The present study was funded by the Child Health Promotion Research Center, Isfahan University of Medical Sciences, and Endocrinology and Metabolism Research Center of Tehran University of Medical Sciences.

\section{References}

1. Obesity and metabolic syndrome among a representative sample of Iranian adolescents. Mehrkash M, Kelishadi R, Mohammadian S, Mousavinasab F, Qorbani M, Hashemi ME, et al. Southeast Asian J Trop Med Public Health. 2012;43(3):756.

2. Dietary predictors of childhood obesity in a representative sample of children in north east of Iran. Baygi F, Qorbani M, Dorosty AR, Kelishadi R, Asayesh H, Rezapour A, et al. Zhongguo Dang Dai Er Ke Za Zhi. 2013;15(7):501.

3. Determinants of childhood obesity in representative sample 
of children in north East of iran. Baygi F, Dorosty AR, Kelishadi R, Qorbani M, Asayesh H, Mansourian M, et al. Cholesterol. 2012;2012:875163.

4. Temporal trends and recent correlates in sedentary behaviours in Chinese children. Cui Z, Hardy LL, Dibley MJ, Bauman A. Int J Behav Nutr Phys Act. 2011;8:93.

5. Increased television viewing is associated with elevated body fatness but not with lower total energy expenditure in children. Jackson DM, Djafarian K, Stewart J, Speakman JR. Am J Clin Nutr. 2009;89(4):1031.

6. Obesity and television watching in preschoolers in Greece: the GENESIS study. Manios Y, Kourlaba G, Kondaki K, Grammatikaki E, Anastasiadou A, Roma-Giannikou E. Obesity (Silver Spring). 2009;17(11):2047.

7. Snacking behaviours of adolescents and their association with skipping meals. Savige G, Macfarlane A, Ball K, Worsley A, Crawford D. Int J Behav Nutr Phys Act. 2007;4:36.

8. Trends in energy intake in U.S. between 1977 and 1996: similar shifts seen across age groups. Nielsen SJ, Siega-Riz AM, Popkin BM. Obes Res. 2002;10(5):370.

9. The influence of food portion size and energy density on energy intake: implications for weight management. Ello-Martin JA, Ledikwe JH, Rolls BJ. Am J Clin Nutr. 2005;82(1 Suppl):236S.

10. Soft drink consumption among US children and adolescents: nutritional consequences. Harnack L, Stang J, Story M. J Am Diet Assoc. 1999;99(4):436.

11. Relation between consumption of sugar-sweetened drinks and childhood obesity: a prospective, observational analysis. Ludwig DS, Peterson KE, Gortmaker SL. Lancet. 2001;357(9255):505.

12. Food and drink intake during television viewing in adolescents: the Healthy Lifestyle in Europe by Nutrition in Adolescence (HELENA) study. Rey-Lopez JP, Vicente-Rodriguez G, Repasy J, Mesana MI, Ruiz JR, Ortega FB, et al. Public Health Nutr. 2011;14(9):1563.

13. Association of physical activity and dietary behaviours in relation to the body mass index in a national sample of Iranian children and adolescents: CASPIAN Study. Kelishadi R, Ardalan G, Gheiratmand R, Gouya MM, Razaghi EM, Delavari A, et al. Bull World Health Organ. 2007;85(1):19.

14. Methodology and Early Findings of the Third Survey of CASPIAN Study: A National School-based Surveillance of Students' High Risk Behaviors. Kelishadi R, Heshmat R, Motlagh ME, Majdzadeh R, Keramatian K, Qorbani M, et al. Int J Prev Med. 2012;3(6):394

15. Validation of a new self-report instrument for measuring physical activity. Aadahl M, Jorgensen T. Med Sci Sports Exerc. 2003;35(7):1196.

16. [Assessment of physical activity in adolescents of Isfahan]. Kelishadi R, Rabiee K, Khosravi A, Famori F, Sadeghi M, Roohafza H. J Shahrekord Univ Med Sci. 2001;3(7):55.

17. International physical activity questionnaire: 12-country reliability and validity. Craig CL, Marshall AL, Sjostrom M, Bauman AE, Booth ML, Ainsworth BE, et al. Med Sci Sports Exerc. 2003;35(8):1381.

18. National and subnational mortality effects of metabolic risk factors and smoking in Iran: a comparative risk assessment. Farzadfar F, Danaei G, Namdaritabar H, Rajaratnam JK, Marcus JR, Khosravi A, et al. Popul Health Metr. 2011;9(1):55.

19. Association between neighborhood socioeconomic status and screen time among pre-school children: a cross-sectional study. Carson V, Spence JC, Cutumisu N, Cargill L. BMC Public Health. 2010;10:367.

20. Longitudinal and secular trends in physical activity and sedentary behavior during adolescence. Nelson MC, Neumark-Stzainer D, Hannan PJ, Sirard JR, Story M. Pediatrics. 2006;118(6):e1627.

21. Trends in child overweight rates and energy intake in France from 1999 to 2007: relationships with socioeconomic status. Lioret S, Touvier M, Dubuisson C, Dufour A, Calamassi-Tran G, Lafay L, et al. Obesity (Silver Spring). 2009;17(5):1092.

22. Trends in vigorous physical activity and TV watching of adolescents from 1986 to 2002 in seven European Countries. Samdal O, Tynjala J, Roberts C, Sallis JF, Villberg J, Wold B. Eur J Public Health. 2007;17(3):242.

23. Temporal trends in overweight and obesity of children and adolescents from nine Provinces in China from 1991-2006. Cui Z, Huxley R, Wu Y, Dibley MJ. Int J Pediatr Obes. 2010;5(5):365.

24. Physical activity, TV viewing, and weight in U.S. youth:1999 Youth Risk Behavior Survey. Eisenmann JC, Bartee RT, Wang MQ. Obes Res. 2002;10(5):379.

25. The prevalence of leisure time sedentary behaviour and physi cal activity in adolescent boys: an ecological momentary assessment approach. Gorely T, Biddle SJ, Marshall SJ, Cameron N. Int J Pediatr Obes. 2009;4(4):289.

26. Modifiable characteristics associated with sedentary behaviours among youth. Leatherdale ST, Wong SL. Int J Pediatr Obes. 2008;3(2):93.

27. Sedentary behaviours among Australian adolescents. Hardy LL Dobbins T, Booth ML, Denney-Wilson E, D.kely A. Aust N Z J Public Health. 2006;30(6):534.

28. Descriptive epidemiology of small screen recreation among Australian adolescents. Hardy LL, Dobbins TA, Denney-Wilson EA, Okely AD, Booth ML. J Paediatr Child Health. 2006;42(11):709.

29. Association of obesity with physical activity, television programs and other forms of video viewing among children in Mexico city. Hernandez B, Gortmaker SL, Colditz GA, Peterson KE, Laird NM, Parra-Cabrera S. Int J Obes Relat Metab Disord. 1999;23(8):845.

30. Physical activity and sedentary lifestyle among children from private and public schools in Northern Brazil. Oliveira TC, Silva AA, Santos Cde J, Silva JS, Conceicao SI. Rev Saude Publica. 2010;44(6):996.

31. Physical activity and inactivity in Chinese school-aged youth: the China Health and Nutrition Survey. Tudor-Locke C, Ainsworth BE, Adair LS, Du S, Popkin BM. Int J Obes Relat Metab Disord. 2003;27(9):1093.

32. Predictors and health consequences of screen-time change during adolescence-1993 Pelotas (Brazil) birth cohort study. Dumith SC, Garcia LM, da Silva KS, Menezes AM, Hallal PC. J Adolesc Health. 2012;51(6 Suppl):S16.

33. Psychosocial and environmental correlates of adolescent sedentary behaviors. Norman GJ, Schmid BA, Sallis JF, Calfas KJ, Patrick K. Pediatrics. 2005;116(4):908.

34. Sociodemographic and home environment predictors of screen viewing among Spanish school children. Hoyos Cillero I, Jago R. J Public Health (Oxf). 2011;33(3):392.

35. Determinants of physical activity and sedentary behaviour in young people: a review and quality synthesis of prospective studies. Uijtdewilligen L, Nauta J, Singh AS, van Mechelen W, Twisk JW, van der Horst K, et al. Br J Sports Med. 2011;45(11):896.

36. Should we be concerned about children spending extended periods of time in sedentary pursuits even among the highly active? Salmon J, Dunstan D, Owen N. Int J Pediatr Obes. 2008;3(2):66.

37. Screen time and physical activity during adolescence: longitudinal effects on obesity in young adulthood. Boone JE, GordonLarsen P, Adair LS, Popkin BM. Int J Behav Nutr Phys Act. 2007;4:26.

38. Schoolwide food practices are associated with body mass index in middle school students. Kubik MY, Lytle LA, Story M. Arch Pediatr Adolesc Med. 2005;159(12):1111.

39. Racial and socioeconomic disparities in nutrition behaviors: targeted interventions needed. Fahlman MM, McCaughtry N, Martin J, Shen B. J Nutr Educ Behav. 2010;42(1):10.

40. Dietary intake patterns of low-income urban african-american adolescents. Wang Y, Jahns L, Tussing-Humphreys L, Xie B, Rockett H, Liang H, et al. J Am Diet Assoc. 2010;110(9):1340.

41. Secular trends in the association of socio-economic position with self-reported dietary attributes and biomarkers in the US population: National Health and Nutrition Examination Survey (NHANES) 1971-1975 to NHANES 1999-2002. Kant AK, Graubard BI. Public Health Nutr. 2007;10(2):158.

42. Academic performance of Korean children is associated with dietary behaviours and physical status. Kim HY, Frongillo EA, Han SS, Oh SY, Kim WK, Jang YA, et al. Asia Pac J Clin Nutr. 2003;12(2):186.

43. Associations of breakfast skipping with obesity and healthrelated quality of life: evidence from a national survey in Taiwan. Huang CJ, Hu HT, Fan YC, Liao YM, Tsai PS. Int J Obes (Lond). 2010;34(4):720.

44. Adolescent breakfast skipping: an Australian study. Shaw ME. 


\section{Baygi F et al.}

Adolescence. 1998;33(132):851.

45. Breakfast skipping and related factors in children in poverty. June KJ, Kim JY, Park S, Lee JY. J Korean Acad Community Health Nur. 2011;22(2):204.

46. Variation in meal-skipping rates of Korean adolescents according to socio-economic status: results of the Korea Youth Risk Behavior Web-based Survey. Hong S, Bae HC, Kim HS, Park EC. J Prev Med Public Health. 2014;47(3):158.

47. Breakfast skipping and health-compromising behaviors in adolescents and adults. Keski-Rahkonen A, Kaprio J, Rissanen A, Virk- kunen M, Rose RJ. Eur J Clin Nutr. 2003;57(7):842.

48. Breakfast and lunch meal skipping patterns among fourth-grade children from selected public schools in urban, suburban, and rural maryland. Gross SM, Bronner Y, Welch C, Dewberry-Moore N, Paige DM. J Am Diet Assoc. 2004;104(3):420. 